\title{
COVID-19: Risk Groups, Mechanistic Insights, and Challenges
}

\author{
Richard Stein ${ }^{1}$ \\ ${ }^{1}$ New York University Tandon School of Engineering
}

April 28, 2020

\begin{abstract}
$\mathrm{N} / \mathrm{A}$

As Dr. Thomson eloquently notes in his valuable letter [1], underlying respiratory diseases appear to be less of a risk factor for poor outcome in COVID-19 patients than either underlying cardiovascular disease or diabetes. This intriguing finding emerged from several studies that examined underlying medical conditions in COVID-19 patients.

In a single-center retrospective analysis of critically ill adults admitted to the intensive care unit of a hospital from China between late December 2019 and January 26, 2020, 22\% of the non-survivors had cerebrovascular disease, $22 \%$ had diabetes, and $6 \%$ had chronic respiratory disease [2]. The analysis of data from patients with laboratory-confirmed COVID-19 from hospitals in China through January 29, 2020 found that 16.2\% of those with serious disease had diabetes, $23.7 \%$ had hypertension, and $3.5 \%$ had chronic obstructive pulmonary disease [3]. A study of electronical medical records of COVID-19 patients admitted between January 16 and February 3, 2020 to a hospital from Wuhan found that hypertension and diabetes mellitus, the most common comorbidities, were present in $37.9 \%, 13.8 \%$, of the patients with severe disease, respectively, but only in $3.4 \%$ of the patients with chronic obstructive pulmonary disease [4]. Finally, an analysis of all COVID-19 cases reported through February 11, 2020, extracted from the Infectious Disease Information System in China, found that case fatality rates in individuals with cardiovascular disease, chronic respiratory disease, and diabetes were $10.5 \%, 6.3 \%$, and $7.3 \%$ respectively, as compared to $0.9 \%$ among patients with no comorbidities [5]. In a case series of COVID-19 patients hospitalized in Wuhan, China, ICU patients were more likely to have underlying diabetes than patients that did not receive ICU care (22.2\% vs $5.9 \%)$ [6].
\end{abstract}

The studies mentioned above did not stratify patients by therapies they were receiving. However, one commonality between cardiovascular disease and diabetes is that they are often treated with angiotensinconverting enzyme (ACE) inhibitors and angiotensin II type-I receptor blockers (ARBs), widely used to inhibit the formation and action of angiotensin II.

ACE shares $42 \%$ amino acid identity with ACE2 [7], a membrane-bound aminopeptidase [8] extensively expressed on type II human alveolar cells [9]. The genes encoding these two proteins are thought to have emerged by duplication [10]. ACE2 is distributed on many tissues and shows highest expression levels in the heart, kidney, lung, small intestine, and testis [11]. On the apical surface of polarized respiratory epithelial cells, ACE2 is a crucial and primary receptor for the cellular entry of SARS-CoV, the virus that caused the 2002-2003 SARS outbreak [12-16]. SARS-CoV binding to ACE2 mediates entry into human or animal cells [17]. ACE2 is also the receptor for SARS-CoV-2, the etiologic agent of COVID-19 [18]. Structural analyses indicate that SARS-CoV-2 binds the ACE2 receptor with a 10-20-fold higher affinity than SARS-CoV [19, $20]$.

The entry of SARS-CoV and SARS-CoV-2 into their target cells is mediated by the viral spike (S) glycoprotein, which is located on the outer envelope of the virion [21]. The S glycoprotein has two functional subunits, 
S1, which binds the cellular receptor, and S2, which contains domains required for the fusion between viral and cellular membranes $[22,23]$. Viral binding and membrane fusion represent the initial and critical steps during the infection cycle of the coronavirus [24] and the first step in establishing the infection [25, 26]. Binding is followed by internalization of ACE2 and down-regulation of its activity on the cell surface [27-29].

SARS-CoV binds ACE2 through a region of the viral S1 subunit called the minimal receptor-binding domain (RBD) [17]. RBD is the most important determinant of the SARS-CoV host range, and studies about the "species jump" during the 2002-2003 SARS outbreak revealed that changes of only one or two amino acids in this region were sufficient to make the virus "jump" to a new host [26, 30, 31].

ACE and ACE2 are two members of the renin angiotensin system that negatively regulate each other [32, 33] and are distinct in their substrate specificity and function [34]. ACE converts angiotensin I to angiotensin II and mediates aldosterone release, vasoconstriction, sodium retention, cell proliferation, and organ hypertrophy [35]. ACE2 cleaves a single residue from angiotensin I to form angiotensin-(1-9), and a single residue from angiotensin II to form angiotensin-(1-7). In humans, ACE2 has a 400-fold higher catalytic efficiency when it uses angiotensin II as a substrate as compared to when it uses angiotensin I [36]. ACE2 and angiotensin-(1-7), through the Mas receptors, oppose ACE and mediate vasodilation and anti-proliferative, anti-hypertrophic, cardioprotective, and reno-protective effects [8,35, 37]. ACE2 has physiological and pathological importance [25] and its dysregulation was implicated in heart disease, hypertension, and diabetes [36, 38-40]. ACE2 is not inhibited by ACE inhibitors [32] and several studies indicate that the ACE2/Angiotensin-(1-7)/Mas axis has anti-inflammatory effects $[41,42]$.

It was recently hypothesized that treatment with ACE inhibitors and/or ARBs may lead to ACE2 overexpression and this could increase the risk of severe COVID-19 [43], possibly by increasing the internalization of SARS-CoV-2. Several lines of evidence indicate that pharmacological manipulation of the renin-angiotensinaldosterone pathway could affect ACE2 receptor levels. In animal studies, the selective blockade of angiotensin II synthesis or activity increased cardiac Ace2 gene expression and activity [44, 45], and treatment with ARBs increased the levels of cardiovascular ACE2 receptors [46-49]. While this link is thought-provoking as a possibility, there isn't currently sufficient evidence to contemplate changing patients' existing therapeutic regimens in order to minimize their risk of COVID-19 complications. The first clinical evidence exploring this link indicated that the use of ACEI and ARBs appear to improve the clinical outcome of COVID-19 patients with hypertension [50]. We will only learn about any possible associations, along with their magnitude and direction, from carefully conducted and adequately powered clinical trials.

It is also important to consider that an increase in ACE2 levels does not necessarily entail a negative impact for the course of COVID-19. ACE2, by forming angiotensin-(1-7) from angiotensin II, could diminish the deleterious effects of angiotensin II and, consequently, it is also possible that ACE inhibitors or ARBs could, in fact, lower the risk of complications [51]. However, increased ACE2 and the formation of angiotensin(1-7), by inhibiting COX-2, could exert anti-inflammatory effects $[52,53]$, underscoring the multitude of possible effects and the need to conduct studies to interrogate these connections. Finally, it is not known whether an increase in the expression of ACE2 would also lead to an increased shedding and increased levels of soluble ACE2, which could act as a decoy receptor and lower viral entry into cells [54]. In support of this, recombinant human ACE2 ameliorated the lung injury induced by the avian influenza H5N1 virus in mice [55]. It is also important to consider that from the relatively limited amount of human data, plasma ACE2 activity does not appear to be statistically different between individuals taking ACE inhibitors or ARBs and those not taking these medications, but these results do not reflect the levels of cellular receptors [56]. Structural analyses indicate that the binding of the SARS-CoV spike protein to ACE2 does not occlude the catalytically active site of the receptor $[26,57]$, and it was hypothesized that angiotensin II binding to ACE2 could induce a conformational change in the receptor, which will no longer be favorable for SARS-CoV-2 binding [54]. The mining of existing datasets, preclinical studies, and clinical trials will help shed light on these complex and sometimes conflicting scenarios.

A decrease in the number of ACE2 receptors appears to be involved in acute lung injury and cardiovascular pathology [58, 59], and may be detrimental during coronavirus infection. A mouse Ace2 knockout developed 
severe cardiac contractility defects and increased angiotensin II levels, and the additional deletion of Ace rescued this phenotype [60]. In acute lung injury models, the loss of Ace2precipitated severe acute lung failure, and this was attenuated by the exogenous recombinant human ACE2 in both Ace2 knock-out and in wild-type mice [59]. Attenuation of the Ace2 catalytic function perturbed the pulmonary renin-angiotensinaldosterone system and increased inflammation and vascular permeability [61], and Ace2 overexpression decreased lung inflammation in an animal model of acute lung injury [62]. In vitro and in experimental animals, SARS-CoV and the SARS-CoV spike protein downregulated ACE2 expression [12, 28]. In mice with lung injury, injection of the SARS-CoV spike protein worsened the acute lung failure and caused lung edema, increased vascular permeability, and decreased lung function, and this pathology was attenuated by blocking the renin-angiotensin-aldosterone pathway [12]. Thus, animals infected with SARS-CoV or treated with the spike protein resemble Ace2 knockout animals [12]. It is relevant that a pilot study of patients with acute respiratory distress syndrome reported the accumulation of angiotensin I and the decrease of angiotensin-(1-9), indicating decreased ACE2 activity, among non-survivors [63]. Thus, SARS-CoV and SARS-CoV-2 might contribute to severe respiratory symptomatology partly because the viruses, by binding the ACE2 receptors, also deregulate protective pathways in the lungs.

Thus, either increased or decreased numbers of pulmonary ACE2 receptors may be detrimental during SARSCoV or SARS-CoV-2 infection, most likely for distinct reasons. An increased number of ACE2 receptors may lead to a higher viral load and more severe clinical disease. Diabetes increases ACE2 expression, as shown in several experimental models, and the resulting increased viral load might explain the more severe course of COVID-19 in diabetic patients [64,65]. Interestingly, in a rodent model of diabetes, ibuprofen inhibited the ACE/angiotensin II/angiotensin type 1 receptor axis and enhanced the ACE2/angiotensin-(1-7)/Mas receptor axis [66]. Too few functional ACE2 receptors, which decrease even more as a result of high viral loads and enhanced receptor internalization [67], might exacerbate acute lung injury, increase angiotensin II levels, and alter the balance between pro- and anti-inflammatory responses. It is relevant that in a study on twelve COVID-19 patients from China, plasma angiotensin II levels were markedly elevated as compared to healthy control individuals, and linearly associated with the viral load and with the lung injury [68]. The animal studies that documented an age-dependent decrease in ACE2 expression in the lung and the aortic might also explain, at least in part, the age-dependent increase in the risk of serious COVID-19 complications $[69,70]$.

SARS-CoV can also bind cells through alternative receptors that include the C-type lectins DC-SIGN (dendritic cell-specific intercellular adhesion molecule-3-grabbing non-integrin) and/or L-SIGN (liver/lymph node-SIGN) [14, 71-73]. It will be critical to understand the potential involvement of the same, or alternative receptors in the pathogenesis of COVID-19.

It has been less clear why SARS-CoV and SARS-CoV-2 lead to severe lung disease [57], in contrast to other, previously known coronaviruses, which usually result in mild upper respiratory infections and cause pneumonia only rarely, mostly in newborn, the elderly, and immunocompromised individuals [74-77]. One of the possibilities advanced for SARS is that the burden of viral replication and the immune status of the host may both shape the severity of the infection [57, 78, 79]. The same might be true for COVID-19, and further exploring the link between viral burden, chronic medical conditions, long-term medication usage, and the severity of the infection will be critical.

An important lesson from SARS and MERS is the association between the incubation period and disease severity. For any infectious disease, the incubation period varies among individuals, even for the same outbreak, and depends on the initial infective dose, the speed of pathogen replication within a host, and host defense mechanisms [80]. During the 2002-2003 SARS outbreak, a study in Hong Kong revealed that patients with shorter incubation times developed more severe disease [81]. The same was found in MERS patients from South Korea, where longer incubation times were associated with a lower risk of death [82]. Interestingly, during the SARS outbreak in Hong Kong, healthcare workers, who have a higher infecting dose, had $34 \%$ shorter median incubation times than non-healthcare workers [83]. It will be interesting to examine whether the same is true for SARS-CoV-2, and whether the incubation period is different in COVID- 
19 patients when they are stratified by age, coexisting morbidities, and therapies they receive for chronic diseases. While the association between the incubation period and mortality might simply indicate that the disease was confirmed earlier in patients with longer incubations, and reflect earlier treatment opportunities [82], it is also plausible that high viral loads might mediate the link between the two.

Two factors decisive for the successful control of outbreaks are the ability to isolate asymptomatic individuals and the ability to trace and quarantine their contacts [84, 85]. Several studies reported asymptomatic shedding of SARS-CoV-2, indicating that asymptomatic carriers, or individuals with very mild symptoms, may sustain transmission [86-89]. For example, nearly $18 \%$ of the passengers who tested positive for SARS-CoV-2 on the Diamond Princess cruise ship were asymptomatic [88]. Another valuable finding that emerged from the COVID-19 outbreak analysis in Singapore, and has a strong impact on infection control, is that after becoming asymptomatic, some patients continued to shed the virus for up to several days. In one instance, a patient continued to have detectable respiratory shedding, as shown by PCR, for eight consecutive days after becoming asymptomatic [90]. Another study revealed that several children with COVID-19 persistently tested positive for viral RNA on fecal swabs after their nasopharyngeal cultures became negative. Even though replication-competent virus was not detected in the fecal swabs, this finding leaves open the possibility of SARS-CoV-2 fecal-oral transmission [91]. These findings illustrate the challenges in understanding SARS-CoV-2 transmission and in identifying infected individuals, tracing their contacts, and implementing preparedness plans. One of the absolute requirements, to clarify these questions and overcome these obstacles, is ensuring the prompt and large-scale testing of symptomatic individuals and of their asymptomatic contacts. This, together with the social distancing measures, are currently our only available assets in facing a pandemic that, even though it was preceded by multiple warnings in recent years, is unlike any other infectious disease that we experienced in modern history.

\section{References}

1. Thomson G. COVID-19: social distancing, ACE 2 receptors, protease inhibitors and beyond? Int J Clin Pract 2020: e13503.

2. Yang $\mathrm{X}, \mathrm{Yu} \mathrm{Y}, \mathrm{Xu} \mathrm{J}$ et al. Clinical course and outcomes of critically ill patients with SARS-CoV-2 pneumonia in Wuhan, China: a single-centered, retrospective, observational study. Lancet Respir Med 2020.

3. Guan WJ, Ni ZY, Hu Y et al. Clinical Characteristics of Coronavirus Disease 2019 in China. N Engl J Med 2020.

4. Zhang JJ, Dong X, Cao YY et al. Clinical characteristics of 140 patients infected with SARS-CoV-2 in Wuhan, China. Allergy 2020.

5. Team TNCPERE. Vital surveillances: the epidemiological characteristics of an outbreak of 2019 novel coronavirus disease (COVID-19)-China, 2020. Available at: http://weekly.chinacdc.cn/en/article/id/e53946e2c6c4-41e9-9a9b-fea8db1a8f51 Last accessed on March 7, 2020. China CDC Weekly 2020;2020, 2(8): 113122 .

6. Wang D, Hu B, Hu C et al. Clinical Characteristics of 138 Hospitalized Patients With 2019 Novel Coronavirus-Infected Pneumonia in Wuhan, China. Jama 2020.

7. Roca-Ho H, Riera M, Palau V et al. Characterization of ACE and ACE2 Expression within Different Organs of the NOD Mouse. Int J Mol Sci 2017; 18 .

8. Turner AJ, Hiscox JA, Hooper NM. ACE2: from vasopeptidase to SARS virus receptor. Trends Pharmacol Sci 2004; 25 : 291-4.

9. Mossel EC, Wang J, Jeffers S et al. SARS-CoV replicates in primary human alveolar type II cell cultures but not in type I-like cells. Virology 2008; 372 : 127-35.

10. Donoghue M, Hsieh F, Baronas E et al. A novel angiotensin-converting enzyme-related carboxypeptidase (ACE2) converts angiotensin I to angiotensin 1-9. Circ Res 2000; 87 : E1-9. 
11. Gembardt F, Sterner-Kock A, Imboden H et al. Organ-specific distribution of ACE2 mRNA and correlating peptidase activity in rodents.Peptides 2005; $26: 1270-7$.

12. Kuba K, Imai Y, Rao S et al. A crucial role of angiotensin converting enzyme 2 (ACE2) in SARS coronavirus-induced lung injury. Nat Med 2005; 11 : 875-9.

13. Ren X, Glende J, Al-Falah M et al. Analysis of ACE2 in polarized epithelial cells: surface expression and function as receptor for severe acute respiratory syndrome-associated coronavirus. J Gen Virol2006; 87 : 1691-5.

14. Han DP, Lohani M, Cho MW. Specific asparagine-linked glycosylation sites are critical for DC-SIGNand L-SIGN-mediated severe acute respiratory syndrome coronavirus entry. J Virol 2007;81 : 12029-39.

15. Kuhn JH, Li W, Choe H, Farzan M. Angiotensin-converting enzyme 2: a functional receptor for SARS coronavirus. Cell Mol Life Sci 2004;61 : 2738-43.

16. Li W, Moore MJ, Vasilieva $\mathrm{N}$ et al. Angiotensin-converting enzyme 2 is a functional receptor for the SARS coronavirus. Nature 2003;426 : 450-4.

17. Wong SK, Li W, Moore MJ et al. A 193-amino acid fragment of the SARS coronavirus S protein efficiently binds angiotensin-converting enzyme 2.J Biol Chem 2004; 279 : 3197-201.

18. Guo YR, Cao QD, Hong ZS et al. The origin, transmission and clinical therapies on coronavirus disease 2019 (COVID-19) outbreak - an update on the status. Mil Med Res 2020; 7 : 11.

19. Chen Y, Guo Y, Pan Y, Zhao ZJ. Structure analysis of the receptor binding of 2019-nCoV. Biochem Biophys Res Commun 2020.

20. Wrapp D, Wang N, Corbett KS et al. Cryo-EM structure of the 2019-nCoV spike in the prefusion conformation. Science 2020;367 : 1260-3.

21. Song W, Gui M, Wang X, Xiang Y. Cryo-EM structure of the SARS coronavirus spike glycoprotein in complex with its host cell receptor ACE2. PLoS Pathog 2018; 14 : e1007236.

22. Bosch BJ, van der Zee R, de Haan CA, Rottier PJ. The coronavirus spike protein is a class I virus fusion protein: structural and functional characterization of the fusion core complex. J Virol2003; 77 : 8801-11.

23. Beniac DR, deVarennes SL, Andonov A et al. Conformational reorganization of the SARS coronavirus spike following receptor binding: implications for membrane fusion. PLoS One 2007; 2 : e1082.

24. Li F. Structure, Function, and Evolution of Coronavirus Spike Proteins. Annu Rev Virol 2016; 3 : $237-61$.

25. Hamming I, Cooper ME, Haagmans BL et al. The emerging role of ACE2 in physiology and disease. $J$ Pathol 2007; 212 : 1-11.

26. Li F, Li W, Farzan M, Harrison SC. Structure of SARS coronavirus spike receptor-binding domain complexed with receptor. Science $2005 ; 309$ : 1864-8.

27. Mathewson AC, Bishop A, Yao Y et al. Interaction of severe acute respiratory syndrome-coronavirus and NL63 coronavirus spike proteins with angiotensin converting enzyme-2. J Gen Virol 2008;89 : 2741-5.

28. Glowacka I, Bertram S, Herzog P et al. Differential downregulation of ACE2 by the spike proteins of severe acute respiratory syndrome coronavirus and human coronavirus NL63. J Virol 2010;84 : 1198-205.

29. Haga S, Yamamoto N, Nakai-Murakami C et al. Modulation of TNF-alpha-converting enzyme by the spike protein of SARS-CoV and ACE2 induces TNF-alpha production and facilitates viral entry. Proc Natl Acad Sci U S A 2008; 105 : 7809-14.

30. Becker MM, Graham RL, Donaldson EF et al. Synthetic recombinant bat SARS-like coronavirus is infectious in cultured cells and in mice.Proc Natl Acad Sci U S A 2008; 105 : 19944-9. 
31. Sheahan T, Rockx B, Donaldson E et al. Mechanisms of zoonotic severe acute respiratory syndrome coronavirus host range expansion in human airway epithelium. J Virol 2008; 82 : 2274-85.

32. Danilczyk U, Eriksson U, Crackower MA, Penninger JM. A story of two ACEs. J Mol Med (Berl) 2003; 81 : 227-34.

33. Simoes ESAC, Teixeira MM. ACE inhibition, ACE2 and angiotensin-(1-7) axis in kidney and cardiac inflammation and fibrosis. Pharmacol Res 2016; 107 : 154-62.

34. Mendoza-Torres E, Oyarzun A, Mondaca-Ruff D et al. ACE2 and vasoactive peptides: novel players in cardiovascular/renal remodeling and hypertension. Ther Adv Cardiovasc Dis 2015; 9 : 217-37.

35. Nunes-Silva A, Rocha GC, Magalhaes DM et al. Physical Exercise and ACE2-Angiotensin-(1-7)-Mas Receptor Axis of the Renin Angiotensin System. Protein Pept Lett 2017; 24 : 809-16.

36. Patel VB, Zhong JC, Grant MB, Oudit GY. Role of the ACE2/Angiotensin 1-7 Axis of the ReninAngiotensin System in Heart Failure. Circ Res 2016; 118 : 1313-26.

37. Xia H, Lazartigues E. Angiotensin-converting enzyme 2 in the brain: properties and future directions. J Neurochem 2008; 107 : 1482-94.

38. Uri K, Fagyas M, Kertesz A et al. Circulating ACE2 activity correlates with cardiovascular disease development. J Renin Angiotensin Aldosterone Syst 2016; 17 .

39. Niu MJ, Yang JK, Lin SS et al. Loss of angiotensin-converting enzyme 2 leads to impaired glucose homeostasis in mice. Endocrine 2008;34 : 56-61.

40. Bindom SM, Hans CP, Xia H et al. Angiotensin I-converting enzyme type 2 (ACE2) gene therapy improves glycemic control in diabetic mice.Diabetes 2010; 59 : 2540-8.

41. Rodrigues Prestes TR, Rocha NP, Miranda AS et al. The Anti-Inflammatory Potential of ACE2/Angiotensin(1-7)/Mas Receptor Axis: Evidence from Basic and Clinical Research. Curr Drug Targets2017; 18 : 1301-13.

42. Padda RS, Shi Y, Lo CS et al. Angiotensin-(1-7): A Novel Peptide to Treat Hypertension and Nephropathy in Diabetes? J Diabetes Metab2015; 6 .

43. Fang L, Karakiulakis G, Roth M. Are patients with hypertension and diabetes mellitus at increased risk for COVID-19 infection? Lancet Respir Med 2020.

44. Ferrario CM, Jessup J, Chappell MC et al. Effect of angiotensin-converting enzyme inhibition and angiotensin II receptor blockers on cardiac angiotensin-converting enzyme 2. Circulation2005; 111 : 260510.

45. Keidar S, Kaplan M, Gamliel-Lazarovich A. ACE2 of the heart: From angiotensin I to angiotensin (1-7). Cardiovasc Res 2007;73 : 463-9.

46. Zhong JC, Ye JY, Jin HY et al. Telmisartan attenuates aortic hypertrophy in hypertensive rats by the modulation of ACE2 and profilin-1 expression. Regul Pept 2011; 166 : 90-7.

47. Sukumaran V, Veeraveedu PT, Gurusamy N et al. Cardioprotective effects of telmisartan against heart failure in rats induced by experimental autoimmune myocarditis through the modulation of angiotensinconverting enzyme-2/angiotensin 1-7/mas receptor axis.Int J Biol Sci 2011; 7 : 1077-92.

48. Karram T, Abbasi A, Keidar S et al. Effects of spironolactone and eprosartan on cardiac remodeling and angiotensin-converting enzyme isoforms in rats with experimental heart failure. Am J Physiol Heart Circ Physiol 2005; 289 : H1351-8.

49. Igase M, Strawn WB, Gallagher PE et al. Angiotensin II AT1 receptors regulate ACE2 and angiotensin(1-7) expression in the aorta of spontaneously hypertensive rats. Am J Physiol Heart Circ Physiol2005; 289 : H1013-9. 
50. Meng J, Xiao G, Zhang J et al. Renin-angiotensin system inhibitors improve the clinical outcomes of COVID-19 patients with hypertension.Emerg Microbes Infect 2020; 9 : 757-60.

51. Kuster GM, Pfister O, Burkard T et al. SARS-CoV2: should inhibitors of the renin-angiotensin system be withdrawn in patients with COVID-19? Eur Heart $J 2020$.

52. Chappell MC. Emerging evidence for a functional angiotensin-converting enzyme 2-angiotensin-(1-7)MAS receptor axis: more than regulation of blood pressure? Hypertension 2007;50 : 596-9.

53. Gallagher PE, Cook K, Soto-Pantoja D et al. Angiotensin peptides and lung cancer. Curr Cancer Drug Targets 2011; 11 : 394-404.

54. Perico L, Benigni A, Remuzzi G. Should COVID-19 Concern Nephrologists? Why and to What Extent? The Emerging Impasse of Angiotensin Blockade. Nephron 2020: 1-9.

55. Zou Z, Yan Y, Shu Y et al. Angiotensin-converting enzyme 2 protects from lethal avian influenza A H5N1 infections. Nat Commun 2014;5 : 3594.

56. Ramchand J, Patel SK, Srivastava PM et al. Elevated plasma angiotensin converting enzyme 2 activity is an independent predictor of major adverse cardiac events in patients with obstructive coronary artery disease. PLoS One 2018; 13 : e0198144.

57. Kuba K, Imai Y, Ohto-Nakanishi T, Penninger JM. Trilogy of ACE2: a peptidase in the renin-angiotensin system, a SARS receptor, and a partner for amino acid transporters. Pharmacol Ther 2010;128 : 119-28.

58. Kuba K, Imai Y, Penninger JM. Multiple functions of angiotensin-converting enzyme 2 and its relevance in cardiovascular diseases. Circ $J$ 2013; $77: 301-8$.

59. Imai Y, Kuba K, Rao S et al. Angiotensin-converting enzyme 2 protects from severe acute lung failure. Nature 2005;436 : 112-6.

60. Crackower MA, Sarao R, Oudit GY et al. Angiotensin-converting enzyme 2 is an essential regulator of heart function. Nature 2002;417: 822-8.

61. Jia H. Pulmonary Angiotensin-Converting Enzyme 2 (ACE2) and Inflammatory Lung Disease. Shock 2016; 46 : 239-48.

62. Ye R, Liu Z. ACE2 exhibits protective effects against LPS-induced acute lung injury in mice by inhibiting the LPS-TLR4 pathway. Exp Mol Pathol 2020; 113 : 104350.

63. Reddy R, Asante I, Liu S et al. Circulating angiotensin peptides levels in Acute Respiratory Distress Syndrome correlate with clinical outcomes: A pilot study. PLoS One 2019; 14 : e0213096.

64. Soro-Paavonen A, Gordin D, Forsblom C et al. Circulating ACE2 activity is increased in patients with type 1 diabetes and vascular complications. J Hypertens 2012; 30 : 375-83.

65. Gilbert A, Liu J, Cheng G et al. A review of urinary angiotensin converting enzyme 2 in diabetes and diabetic nephropathy. Biochem Med (Zagreb) 2019; 29 : 010501.

66. Qiao W, Wang C, Chen B et al. Ibuprofen attenuates cardiac fibrosis in streptozotocin-induced diabetic rats. Cardiology 2015;131: 97-106.

67. Deshotels MR, Xia H, Sriramula S et al. Angiotensin II mediates angiotensin converting enzyme type 2 internalization and degradation through an angiotensin II type I receptor-dependent mechanism. Hypertension 2014; 64 : 1368-75.

68. Liu Y, Yang Y, Zhang C et al. Clinical and biochemical indexes from 2019-nCoV infected patients linked to viral loads and lung injury.Sci China Life Sci 2020; 63 : 364-74.

69. Xie X, Chen J, Wang X et al. Age- and gender-related difference of ACE2 expression in rat lung. Life Sci 2006; 78 : 2166-71. 
70. Yoon HE, Kim EN, Kim MY et al. Age-Associated Changes in the Vascular Renin-Angiotensin System in Mice. Oxid Med Cell Longev2016; 2016 : 6731093.

71. Du L, He Y, Zhou Y et al. The spike protein of SARS-CoV-a target for vaccine and therapeutic development. Nat Rev Microbiol 2009;7 : 226-36.

72. Shih YP, Chen CY, Liu SJ et al. Identifying epitopes responsible for neutralizing antibody and DC-SIGN binding on the spike glycoprotein of the severe acute respiratory syndrome coronavirus. J Virol 2006;80 : 10315-24.

73. Jeffers SA, Tusell SM, Gillim-Ross L et al. CD209L (L-SIGN) is a receptor for severe acute respiratory syndrome coronavirus. Proc Natl Acad Sci U S A 2004; 101 : 15748-53.

74. El-Sahly HM, Atmar RL, Glezen WP, Greenberg SB. Spectrum of clinical illness in hospitalized patients with "common cold" virus infections. Clin Infect Dis 2000; 31 : 96-100.

75. Folz RJ, Elkordy MA. Coronavirus pneumonia following autologous bone marrow transplantation for breast cancer. Chest 1999;115 : 901-5.

76. Oxford JS, Bossuyt S, Lambkin R. A new infectious disease challenge: Urbani severe acute respiratory syndrome (SARS) associated coronavirus.Immunology 2003; 109 : 326-8.

77. Tse GM, To KF, Chan PK et al. Pulmonary pathological features in coronavirus associated severe acute respiratory syndrome (SARS). J Clin Pathol 2004; 57 : 260-5.

78. Perlman S, Dandekar AA. Immunopathogenesis of coronavirus infections: implications for SARS. Nat Rev Immunol 2005;5 : 917-27.

79. Hung IF, Cheng VC, Wu AK et al. Viral loads in clinical specimens and SARS manifestations. Emerg Infect Dis 2004; 10 : 1550-7.

80. Nishiura H. Early efforts in modeling the incubation period of infectious diseases with an acute course of illness. Emerg Themes Epidemiol 2007; $4: 2$.

81. Virlogeux V, Fang VJ, Wu JT et al. Brief Report: Incubation Period Duration and Severity of Clinical Disease Following Severe Acute Respiratory Syndrome Coronavirus Infection. Epidemiology 2015;26 : 666-9.

82. Virlogeux V, Park M, Wu JT, Cowling BJ. Association between Severity of MERS-CoV Infection and Incubation Period. Emerg Infect Dis2016; 22 : 526-8.

83. Cowling BJ, Muller MP, Wong IO et al. Alternative methods of estimating an incubation distribution: examples from severe acute respiratory syndrome. Epidemiology 2007; $18: 253-9$.

84. Fraser C, Riley S, Anderson RM, Ferguson NM. Factors that make an infectious disease outbreak controllable. Proc Natl Acad Sci U S A 2004; 101 : 6146-51.

85. Peak CM, Childs LM, Grad YH, Buckee CO. Comparing nonpharmaceutical interventions for containing emerging epidemics. Proc Natl Acad Sci U S A 2017; 114 : 4023-8.

86. Bai Y, Yao L, Wei T et al. Presumed Asymptomatic Carrier Transmission of COVID-19. Jama 2020.

87. Chan JF, Yuan S, Kok KH et al. A familial cluster of pneumonia associated with the 2019 novel coronavirus indicating person-to-person transmission: a study of a family cluster. Lancet 2020;395 : 514-23.

88. Mizumoto K, Kagaya K, Zarebski A, Chowell G. Estimating the asymptomatic proportion of coronavirus disease 2019 (COVID-19) cases on board the Diamond Princess cruise ship, Yokohama, Japan, 2020.Eurosurveillance 2020; 25 : 2000180.

89. Tong ZD, Tang A, Li KF et al. Potential Presymptomatic Transmission of SARS-CoV-2, Zhejiang Province, China, 2020. Emerg Infect Dis2020; 26 . 
90. Young BE, Ong SWX, Kalimuddin S et al. Epidemiologic Features and Clinical Course of Patients Infected With SARS-CoV-2 in Singapore.Jama 2020.

91. Xu Y, Li X, Zhu B et al. Characteristics of pediatric SARS-CoV-2 infection and potential evidence for persistent fecal viral shedding. Nature Medicine 2020. 